\title{
Reacciones paradójicas en el tratamiento de la tuberculosis ganglionar
}

\author{
FELIPE ALIAGA T.*, JUAN CARLOS RODRÍGUEZ D.** y VICTORINO FARGA C.***
}

\section{Paradoxical reactions during tuberculosis lymphadenitis treatment}

Lymphadenitis tuberculosis is the most frequent form of non pulmonary tuberculosis. Its incidence has increased in the last years probably because HIV co-infection. Usually manifests like a swelling of lymph nodes in the cervical region without constitutional symptoms. Diagnostics tests yields are poorer than in pulmonary tuberculosis probably due to the scarce bacillus population. Treatment is the same of pulmonary tuberculosis, but paradoxical reactions are far more frequent. These reactions, specially the latest presentations ones very often are treated as recurrence of the disease. Although this is always a possibility, in most cases they are due to an hypersensitivity reaction. In this article we present an illustrative case, an update on tuberculosis lymphadenitis and a review of the paradoxical reactions during its treatment.

Key words: Tuberculous lymphadenitis; lymphadenitis; paradoxical reactions.

\section{Resumen}

La tuberculosis ganglionar es la forma más frecuente de tuberculosis extrapulmonar. Su incidencia ha aumentado, probablemente por la co-infección con VIH. Su presentación clínica más habitual es con un aumento de volumen de los ganglios cervicales sin síntomas constitucionales. Las pruebas diagnósticas tienen menos rendimiento que en la tuberculosis pulmonar por ser una enfermedad con menor población bacilar. Para el tratamiento se utilizan las mismas drogas y duración que en tuberculosis pulmonar, pero existe mayor incidencia de reacciones paradojales, las que pueden ser de dificil manejo. En este artículo presentamos primero un caso clínico particularmente ilustrativo, seguido de una puesta al día sobre tuberculosis ganglionar, incluyendo una revisión sobre el manejo de sus reacciones paradójicas.

Palabras clave: Tuberculosis ganglionar, adenopatías, reacción paradojal.

\section{Caso clínico}

Paciente de sexo femenino de 38 años de edad, ingeniero civil químico, VIH negativo, que consulta el 8 de septiembre del año 2014 por parestesias del brazo izquierdo. Una ecotomografía cervical demuestra la presencia de múltiples adenopatías subclaviculares y cervicales izquierdas (Figura 1). Se practica una biopsia ganglionar que es informada como "Linfonodo con hiperplasia linfoide mixta de tipo reactivo", pero un Xpert MTB/RIF es "positivo bajo" para M. tuberculosis y el cultivo rápido del ganglio (MGIT), revisado por el Instituto de Salud Pública, confirma el desarrollo de M. tuberculosis, sensible a isoniacida, rifampicina y pirazinamida.

El 12 de septiembre de 2014 inicia tratamiento diario con isoniacida, rifampicina y pirazinamida, el que debe ser suspendido el 29 de octubre, cuando ya se apreciaba mejoría clínica y disminución del tamaño de los ganglios, por grave reacción sistémica que demostró deberse a la rifampicina. Reinicia tratamiento antituberculoso el 25 de noviembre con isoniacida, pirazinamida

\footnotetext{
* Becado Servicio Medicina Respiratoria, Instituto Nacional del Tórax (INT).

** Médico Servicio Medicina Respiratoria, INT.

*** Médico Asesor del Ministerio de Salud.
} 


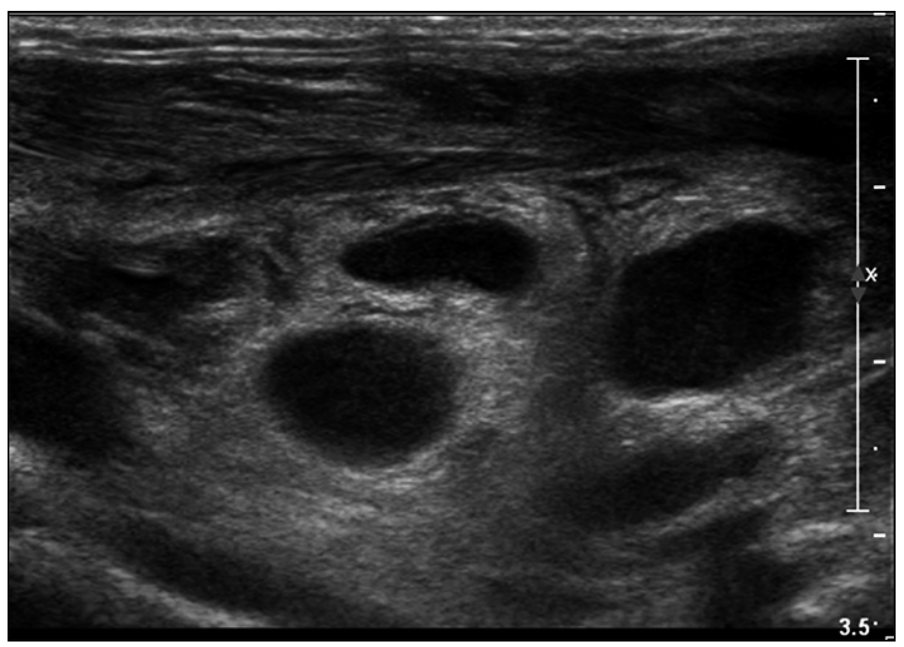

Figura 1. Punción de ganglios bajo ecotomografía. Se estudió región cervical izquierda y comparativamente la derecha. Se definieron múltiples adenopatías de aspecto reactivo en las cadenas cervicales y subclaviculares a izquierda. No se observaron áreas líquidas en el espesor de los ganglios, los cuales mostraron vasos hasta la periferia con la señal Doppler color. Hay edema del tejido subcutáneo que rodea a los ganglios (11-09-2014).

y moxifloxacino, esquema que fue bien tolerado y se mantuvo en su fase diaria e intermitente de 3 veces por semana hasta su término el $1^{\circ}$ de mayo del año 2015.

Consulta nuevamente, estando en pleno tratamiento, el 10 de diciembre de 2014, por aumento de tamaño de todos los ganglios. El 22 de diciembre se decide agregar prednisona, $20 \mathrm{mg}$ diarios, con lo cual se controla una inflamación dolorosa que se había presentado en la zona, apreciándose una discreta reducción de los ganglios. Se fueron disminuyendo las dosis de prednisona, y al suspender la droga, el 12 de enero de 2015, vuelven a crecer las adenopatías y se tornan sensibles. Nuevamente se observa mejoría sintomática al reiniciar $20 \mathrm{mg}$ de prednisona el 14 de enero.

En esta etapa se aprecia que la cicatriz de la biopsia original está inestable a partir de un trayecto fistuloso que drena pequeñas cantidades de material caseoso intermitentemente. Esta vez la reducción progresiva de las dosis de prednisona fue más lenta; sin embargo, una semana después de suspenderla, el 14 de julio de 2015, se aprecia un nuevo aumento del tamaño de los linfonodos con nuevos signos inflamatorios locales.

Como el tratamiento antituberculoso había terminado dos meses antes, se planteó la posibilidad de una reactivación de la enfermedad. Pero, como se verá más adelante, la literatura médica enseña que la mayoría de las reacciones paradójicas durante o después de un tratamiento exitoso, no se deben a recaídas bacteriológicas sino a reacciones de hipersensibilidad retardada a los antígenos de bacilos muertos y, por lo tanto, no requieren nuevas terapias. Sin embargo, como se verá después, siempre es conveniente descartar una verdadera reactivación de la tuberculosis.
Se procedió a la punción del ganglio mayor para su estudio bacteriológico, La baciloscopia del material obtenido fue negativa y su análisis por PCR (Xpert TB/RIF) informó "detección baja de ADN MTB" (que en este caso presuntamente sería de bacilos no viables). Los cultivos rápidos y lentos (líquidos y sólidos estándar) fueron subsecuentemente todos negativos. También se practicó una Tomografía Computarizada de tórax y abdomen que sólo mostró las mismas adenopatías cervicales visualizadas por las sucesivas ecografías cervicales.

El 6 de agosto de 2015 se reinició el empleo de prednisona $20 \mathrm{mg}$ diarios, con reducciones más lentas de las dosis, pero al llegar a $10 \mathrm{mg}$ diarios, la disminución progresiva de los ganglios se detuvo y empezaron a aparecer signos inflamatorios locales. El ganglio mayor enrojeció la piel vecina y amenazó con fistulizarse. Ante la alternativa de tener que mantener dosis elevadas de prednisona por largos períodos, sin tener certeza del control final de la enfermedad, se decidió seguir con la dosis de $10 \mathrm{mg}$ diarios y monitorear la evolución espontánea del proceso. Por fin, el 28 de marzo del año 2016, el ganglio mayor se fistulizó, drenando abundante material caseoso. Posteriormente, la enfermedad ha entrado en una fase de lenta curación espontánea, como se observaba antes del advenimiento de los modernos tratamientos antituberculosos, aunque con la persistencia de varias adenopatías (Figura 2).

Cabe agregar que la evolución de esta paciente fue monitorizada a través de tres presentaciones a las Reuniones de Tuberculosis del Instituto Nacional del Tórax, en las que se acordaron las distintas medidas terapéuticas. Durante su evolución se consultaron muchas opiniones y hasta se 


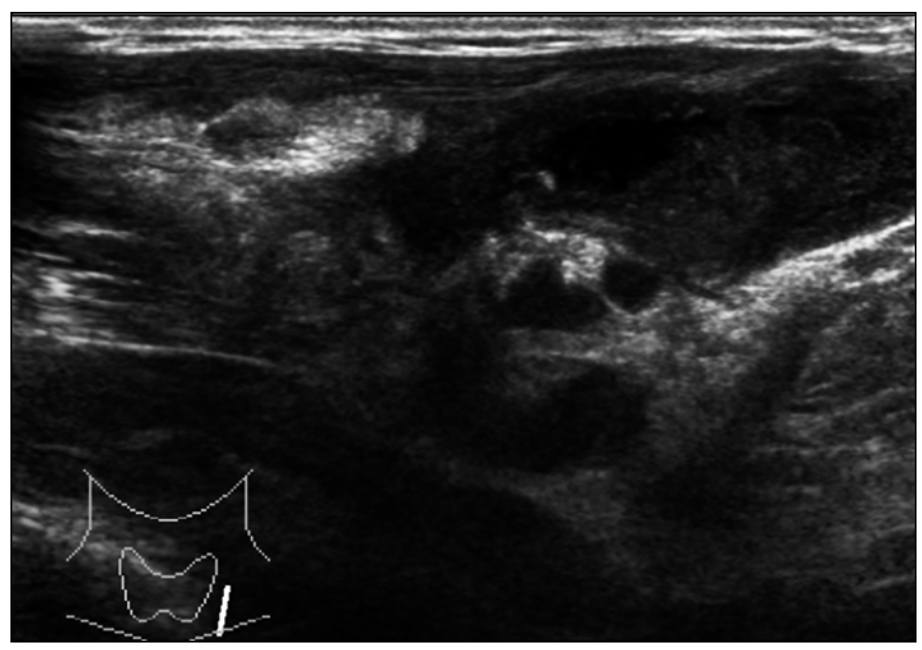

Figura 2. Control ecotomográfico (24-112015). Los ganglios ubicados en la región supraclavicular izquierda y yugular inferior están de leve menor tamaño que en los estudios anteriores. planteó la resección quirúrgica de los ganglios, la que en estos casos debe ser excepcional y más bien reservada como una cirugía reparadora de cicatrices antiestéticas que puedan quedar.

Este caso, aunque es excepcional que se produzcan tantas reacciones paradojales y que estas sean refractarias a dosis moderadas de corticoesteroides, refleja muy bien las serias dificultades que pueden presentarse en el manejo de estos pacientes.

\section{Tuberculosis ganglionar}

La tuberculosis ganglionar o linfadenitis tuberculosa es la forma más frecuente de tuberculosis extrapulmonar ${ }^{1,2}$. Según su ubicación se divide en intratorácica y extratorácica, esta última es llamada también linfadenitis periférica. Su localización más habitual en la región cervical se conoce como escrófula desde la antigüedad ${ }^{3}$.

\section{Epidemiología}

Tanto en Estados Unidos (USA) como en Chile la incidencia de la tuberculosis (TBC) ha disminuido. Así USA presenta unas tasas de 2,96 casos por 100.000 habitantes el año 2014 y Chile 13,5 por 100.000 el $2013^{4,5}$. En cambio, los casos de localización extrapulmonar han aumentado en la mayoría de los países. En Corea del Sur la TBC extrapulmonar aumentó de un $14 \%$ a un $20 \%$ al comparar los períodos comprendidos entre los años 2005-2007 y 2010-2013 ${ }^{6}$. El año 2014 el Centro para el Control y Prevención de Enfermedades (CDC) informó que en EE. UU. el 20,6\% de los casos de TBC correspondieron a $\mathrm{TBC}$ extrapulmonar. Entre éstas la más frecuente es la ganglionar con un 38,2\% de todas las formas extrapulmonares. En Chile, según el último informe del Ministerio de Salud, el 25\% de los casos de TBC son extrapulmonares y de ellos el año 2014, se notificaron 136 casos de TBC ganglionar, 22 de ellos coinfectados con $\mathrm{VIH}^{5}$.

Entre los grupos de mayor incidencia de esta localización están los coinfectados por VIH y los extranjeros provenientes de áreas donde la TBC es endémica. En los primeros la incidencia está inversamente relacionada con los niveles de linfocitos T CD4; por su parte, los extranjeros presentan una tasa 13 veces mayor, siendo los provenientes de Asia los de mayor riesgo ${ }^{3,7}$.

La epidemiología también varía según el grado de desarrollo de un país, lo que está estrechamente relacionado con el control de la TBC en él. En países donde esta enfermedad es endémica ( $>40$ casos por 100.000 habitantes), existe mayor coinfección con VIH, llegando hasta un $49 \%$ de los casos, y también mayor compromiso pulmonar asociado a la TBC ganglionar ${ }^{3,7}$. En la mayoría de las series esta enfermedad es más frecuente en mujeres que en hombres en relación 1,4-1,7 a 1, a diferencia de lo que ocurre en la TBC pulmonar que es más frecuente en los hombres. Con respecto a la edad, anteriormente la TBC ganglionar era considerada una enfermedad de la infancia, actualmente su frecuencia se ha desplazado a pacientes adultos, de edades promedio entre 3040 años ${ }^{8}$.

En los países donde la TBC no es endémica la mayoría de los casos ocurre en adultos inmigrantes provenientes de países donde la TBC es más prevalente. En un estudio realizado en Francia, Clevenbergh y cols. reportaron que el $68 \%$ de los casos de TBC ganglionar provenían de India, 
Pakistán o África Sub-Sahariana ${ }^{7}$. No está muy claro el por qué, pero una observación recurrente es que en los países no endémicos existe una predilección por la TBC ganglionar en inmigrantes provenientes del Sudeste asiático e India 9 .

\section{Patogenia}

Las vías de infección varían de acuerdo al sitio ganglionar afectado. En el compromiso cervical se produciría por contacto directo de los bacilos con el anillo de Waldeyer y a través de éste por diseminación y afección de los grupos ganglionares adyacentes. En la forma ganglionar periférica el mecanismo patogénico más frecuente sería la reactivación de una infección por TBC primaria pulmonar diseminada anteriormente por vía hematógena. También está descrita la tuberculosis ganglionar abdominal por Mycobacterium bovis, secundaria a ingestión de leche de vaca no pasteurizada, la que está en franco descenso y sólo ocurre en países menos desarrollados ${ }^{14}$.

\section{Manifestaciones clínicas}

La forma más habitual de presentación de la TBC ganglionar periférica es la aparición, lentamente progresiva, de adenopatías cervicales unilaterales no dolorosas, lo que ocurre hasta en un $83 \%$ de los casos. Otros grupos ganglionares menos afectados son los axilares y los mediastínicos ${ }^{3,8}$. El compromiso bilateral está descrito en un $26 \%$ y es más frecuente en pacientes VIH positivos $^{10,11}$.

La mayor parte de los enfermos se presentan con ganglios entre 1 y $3 \mathrm{~cm}$ de diámetro aunque hasta en un tercio de los casos pueden ser mayores a $3 \mathrm{~cm}$. En un estudio reciente en Túnez de 203 casos de TBC ganglionar en pacientes VIH negativos, el $54 \%$ tenía ganglios entre 1 y $3 \mathrm{~cm}$ y el $34 \%$ al ser medidos por ecografía o tomografía axial computada (TAC) eran mayores a $3 \mathrm{~cm}^{8}$.

Habitualmente el aumento de tamaño de los linfonodos es paulatino y la piel circundante es de aspecto normal. A medida que la enfermedad avanza los ganglios se vuelven firmes y adheridos a planos profundos, pudiéndose observar en la piel cambios inflamatorios locales. En algunos casos pueden abscedarse y ulcerarse, formando trayectos fistulosos. Como otra complicación está descrita la compresión de estructuras vecinas (bronquios, esófago, grandes vasos) especialmente en las adenopatías mediastínicas, lo que puede determinar el desarrollo de atelectasias, bronquiectasias y hasta quilotórax. También han sido comunicadas la disfagia por compromiso esofágico y la compresión del nervio laríngeo recurrente ${ }^{13}$.
Respecto a los síntomas constitucionales, éstos son menos frecuentes que en la TBC pulmonar. En los pacientes VIH (-) la presencia de fiebre varía entre un 20 a $30 \%$. En una serie de 121 casos de la India el porcentaje de enfermos con fiebre fue de $23 \%$. A su vez, Smaoui y cols. en una serie reciente de 181 casos en Túnez reportó un $21 \%$ de fiebre. Otros síntomas son: baja de peso en un $32 \%$ y sudoración nocturna en un $11 \%{ }^{8}$. En los pacientes VIH (+) la frecuencia de fiebre es mayor y se presenta entre 40 y $80 \%$ de los casos; la baja de peso y sudoración nocturna son también más frecuentes ${ }^{10,12}$. Por último, la presencia de TBC pulmonar concomitante varía entre 18 y $42 \%$ y es también más frecuente en portadores $\mathrm{VIH}(+)^{3}$.

\section{Diagnóstico}

En la tuberculosis ganglionar y en las tuberculosis extrapulmonares, en general el diagnóstico es más difícil por la existencia de una menor población bacilar, lo que determina un menor rendimiento de las pruebas diagnósticas microbiológicas. Además, cuando existe compromiso mediastínico sin compromiso de ganglios periféricos, la toma de muestras se torna más complicada, surgiendo así la necesidad de disponer de herramientas de apoyo diagnóstico más invasivas ${ }^{13}$.

El diagnóstico definitivo y el "gold estándar" continúa siendo el cultivo positivo para $M$. tuberculosis, el que demora en sus resultados desde 2 semanas hasta 2 meses. Las baciloscopias de tejido ganglionar pueden confirmar el diagnóstico, aunque su sensibilidad es baja (Tabla 1).

Las muestras para el estudio ganglionar pueden obtenerse a través de la punción aspirativa con aguja fina (PAAF) o por la biopsia quirúrgica, ya sea directamente o apoyada con estudios de imágenes como ecografía, tomografía axial computarizada (TAC) y endosonografía bronquial (EBUS).

La PAAF debería ser el primer test diagnóstico a realizar por ser poco invasiva, segura, de bajo costo y por tener una sensibilidad razonable, especialmente en áreas de alta prevalencia de TBC. Su mayor ventaja radica en la rapidez con que son entregados sus resultados. La positividad de la baciloscopia en el material aspirado en diferentes estudios en promedio es de $25 \%$, con variaciones entre 8 y $38 \%$ y para el cultivo, en promedio de $40 \%$, con variaciones entre $10 \mathrm{y}$ $92 \%$.

La biopsia excisional es más sensible que la PAAF y debe realizarse cuando el resultado de esta última sea negativo. Deben recogerse muestras ganglionares separadas para su estudio mi- 
Tabla 1. Rendimiento de los tests diagnósticos en la tuberculosis ganglionar

\begin{tabular}{|c|c|c|c|c|}
\hline Estudio & Baciloscopia & Cultivo & Histología & AAN \\
\hline $\begin{array}{l}\text { Fain, Francia }(1999)^{31} \\
\text { PAAF } \\
\text { BE }\end{array}$ & $\begin{array}{ll}2 / 26 & (8 \%) \\
2 / 39 & (5 \%)\end{array}$ & $\begin{array}{r}8 / 26(31 \%) \\
12 / 39(31 \%)\end{array}$ & $\begin{array}{l}\text { NR } \\
32 / 39(82 \%)\end{array}$ & $\begin{array}{l}\text { NR } \\
\text { NR }\end{array}$ \\
\hline $\begin{array}{l}\text { Singh, India }(2000)^{32} \\
\text { PAAF } \\
\text { BE }\end{array}$ & $\begin{array}{l}4 / 22(18 \%) \\
5 / 22(23 \%)\end{array}$ & $\begin{array}{l}2 / 22(10 \%) \\
4 / 22(18 \%)\end{array}$ & $\begin{array}{r}7 / 22(32 \%) \\
13 / 22(59 \%)\end{array}$ & $\begin{array}{l}12 / 22(55 \%) \\
15 / 22(68 \%)\end{array}$ \\
\hline $\begin{array}{l}\text { Polesky, EEUU }(2005)^{12} \\
\text { PAAF } \\
\text { BE }\end{array}$ & $\begin{array}{r}5 / 19(26 \%) \\
15 / 39(38 \%)\end{array}$ & $\begin{array}{l}48 / 77(62 \%) \\
24 / 34(71 \%)\end{array}$ & $\begin{array}{l}47 / 76(62 \%) \\
31 / 36(88 \%)\end{array}$ & $\begin{array}{l}\text { NR } \\
\text { NR }\end{array}$ \\
\hline $\begin{array}{l}\text { Clevenberg, Francia }(2010)^{7} \\
\text { PAAF } \\
\text { BE }\end{array}$ & $\begin{array}{r}21 / 36(38 \%) \\
6 / 20(30 \%)\end{array}$ & $\begin{array}{l}33 / 36(92 \%) \\
17 / 20(85 \%)\end{array}$ & $\begin{array}{r}13 / 57 \\
(\mathrm{PAAF}+\mathrm{BE})\end{array}$ & $\begin{array}{l}\text { NR } \\
\text { NR }\end{array}$ \\
\hline $\begin{array}{l}\text { Asimacopoulos, UK }(2010)^{22} \\
\text { PAAF }\end{array}$ & $22 / 97 \quad(23 \%)$ & 65/97 (67\%) & 7/97 (79\%) & \\
\hline $\begin{array}{l}\text { Yu, Surcorea }(2015)^{27} \\
\text { PAAF + BE }\end{array}$ & $148 / 463(32 \%)$ & $106 / 273(39 \%)$ & $309 / 468(66 \%)$ & $263 / 357(74 \%)$ \\
\hline $\begin{array}{l}\text { Salvador, España }(2015)^{15} \\
\text { PAAF } \\
\text { BE }\end{array}$ & $\begin{array}{l}16 / 64(25 \%) \\
10 / 48(20 \%)\end{array}$ & $\begin{array}{l}40 / 64(62 \%) \\
31 / 48(64 \%)\end{array}$ & $\begin{array}{l}40 / 73(54 \%) \\
60 / 62(96 \%)\end{array}$ & $\begin{array}{r}11 / 15(73 \%) \\
6 / 13(46 \%)\end{array}$ \\
\hline $\begin{array}{l}\text { Smaoui, Túnez }(2015)^{8} \\
\text { PAAF } \\
\text { BE }\end{array}$ & $\begin{array}{l}5 / 21(23 \%) \\
5 / 36(13 \%)\end{array}$ & $\begin{array}{l}3 / 11(27 \%) \\
7 / 26(26 \%)\end{array}$ & $166 / 174(95 \%)$ & NR \\
\hline
\end{tabular}

PAAF: Punción con aguja fina. BE: Biopsia escisional. Histología: Granuloma tuberculoídeo. AAN: Amplificación de ácidos nucleicos. NR: No realizado.

crobiológico e histológico. Su sensibilidad para la baciloscopia es alrededor de $30 \%(5-38 \%)$ y para el cultivo alcanza sobre un $50 \%{ }^{3,8,15}$. El estudio histológico de la biopsia demuestra la presencia de granulomas entre 32 y $88 \%$ según las distintas series. Ante una biopsia con granulomas con necrosis caseosa y un cuadro clínico compatible, puede aceptarse el diagnóstico de TBC aún en ausencia de comprobación bacteriológica.

Actualmente se dispone de técnicas de amplificación de ácidos nucleicos (AAN), como la detección de ADN micobacteriano por reacción en cadena de la polimerasa (PCR) del material obtenido por punción o biopsia ganglionar, que resultan muy atractivas porque tienen mayor sensibilidad y una muy buena especificidad. Su gran ventaja radica en la rapidez con que son entregados sus resultados. Es importante recordar que la detección de material genético puede ocurrir con restos de bacilos no viables.

Un gran avance ha sido el advenimiento del Xpert MTB/RIF, que es una prueba automatizada de detección de ácidos nucleicos por PCR. Una revisión reciente por Denkinger y cols., reporta una sensibilidad global sobre un $80 \%$, con especificidad de 94\%. Recientemente la Organización
Mundial de la Salud recomendó el uso de Xpert por sobre los otros test diagnósticos en la tuberculosis ganglionar ${ }^{16,17}$. Sin embargo, hay que tener en cuenta que los resultados negativos no excluyen la enfermedad por lo que si la sospecha es alta, deben utilizarse métodos diagnósticos adicionales. En nuestro país se evaluó el rendimiento del Xpert MTB/RIF tanto en muestras respiratorias como no respiratorias, obteniendo una sensibilidad de $100 \%$ y una especificidad de $94 \%$ en 145 pacientes estudiados ${ }^{18}$.

Los tests inmunológicos como la Reacción de Tuberculina (PPD) y los tests de liberación de interferón gama (IGRAs) pueden ser orientadores, pero tienen un rol muy limitado para el diagnóstico etiológico. Un PPD positivo puede serlo debido a la vacunación BCG y no necesariamente diagnóstico de infección TBC y un PPD (-) tampoco la descarta, ya que infecciones intercurrentes o variaciones de la inmunidad pueden negativizarlo. Asimismo los IGRAs tienen la limitación de no poder distinguir entre una infección latente o enfermedad; además, un resultado negativo tampoco excluye la TBC. Jung y cols. estudiaron la sensibilidad y especificidad de los IGRAs medidos por QUANTIFERON-TB 
Gold en 56 pacientes con TBC extrapulmonar, obteniendo una positividad de un $70 \%$ en todas sus localizaciones. En los 15 pacientes con TBC ganglionar su sensibilidad y especificidad fue mejor, de un $81,8 \%$ y $80 \%$ respectivamente ${ }^{19}$. Sin embargo, la gran variabilidad en los resultados de estas pruebas hace incierta su indicación actual en el diagnóstico de TBC latente o activa.

Los estudios de imágenes son muy útiles tanto en el diagnóstico como en el manejo terapéutico de las linfoadenitis TBC.

La ecografía es una herramienta fundamental, tanto para la caracterización de los ganglios, como para guiar la punción y/o biopsia diagnósticas. A la ultrasonografía los linfonodos suelen ser múltiples, con fusión de ganglios adyacentes y poseen centros hipoecogénicos con realce en su cara posterior ${ }^{3,8}$. Otros hallazgos compatibles con TBC ganglionar incluyen la presencia de finas capas hiperecogénicas y cambios inflamatorios en los tejidos blandos periganglionares ${ }^{30}$.

La tomografía axial computada (TAC) del tórax también puede ser de ayuda en la caracterización inicial de las lesiones, permitiendo estimar con mayor precisión la magnitud del compromiso ganglionar y como guía para la punción o biopsia ganglionar. Además, permite monitorizar la respuesta al tratamiento sobre todo en la localización mediastínica, en la que no es posible la evaluación clínica ni ecográfica en forma precisa.

El diagnóstico etiológico continúa siendo un desafío en algunos casos. La fibrobroncoscopia puede ser una herramienta de apoyo a la biopsia ante adenopatías intratorácicas; además, puede utilizarse en caso de fístulas al árbol traqueobronquial de ganglios mediastínicos. En las adenopatías intratorácicas aisladas, la biopsia transbronquial con aguja guiada por endosonografia bronquial (EBUS) puede ser muy útil, con una sensibilidad diagnóstica de $95 \%{ }^{20}$.

\section{Tratamiento}

El tratamiento farmacológico es la base de la terapia y consiste en la administración de 4 drogas (rifampicina, isoniacida, etambutol y pirazinamida) en fase diaria durante 2 meses y luego continuar con rifampicina e isoniacida en forma trisemanal por 4 meses más, hasta completar seis meses de tratamiento. Esta es la recomendación de las últimas guías clínicas chilenas (2014), como también las de la Sociedad Americana de Tórax (ATS) y de la Sociedad Americana de Enfermedades Infecciosas (IDSA) ${ }^{21,24}$.

Si bien existe una tendencia a prolongar el tratamiento a 9 meses, esta práctica no ofrece mayores ventajas en cuanto a tasas de curación o recaídas ${ }^{25}$. Un estudio que comparó 6 meses versus 9 meses de tratamiento, con seguimiento a 30 meses, no encontró diferencias significativas en tasas de curación y recaídas como tampoco en el desarrollo de nuevos ganglios, aumento del tamaño de éstos o necesidad de tratamiento quirúrgico ${ }^{23}$.

\subsection{Cirugía}

Dada la existencia de una terapia médica efectiva, el manejo quirúrgico de estos pacientes se reserva principalmente a la obtención de ganglios para su estudio histológico y microbiológico. Las guías de la ATS/CDC recomiendan la cirugía sólo ante ganglios de gran tamaño y con tendencia a drenar espontáneamente, sugiriendo para su manejo la incisión y drenaje o aspiración de éstos $^{24}$. Otras indicaciones son la persistencia de ganglios que causen incomodidad o molestias al paciente, o ante reacciones paradójicas que produzcan síntomas similares y que no respondan al tratamiento corticoesteroidal, o cuando éste esté contraindicado. Por último, debe considerarse para casos de linfadenitis TBC localizada multirresistente (TBC-MDR).

En los pacientes con TBC ganglionar la monitorización de la terapia, a diferencia de la TBC pulmonar, no se realiza en base a criterios bacteriológicos, ya que generalmente la toma de nuevas muestras implica procedimientos invasivos, mayor riesgo y costos asociados. La efectividad del tratamiento, por lo tanto, se basa en hallazgos clínicos y ecotomográficos. La respuesta ganglionar es lenta, pudiendo incluso aumentar el tamaño ganglionar durante o después del tratamiento, lo que se conoce como reacciones paradójicas (RP) a las que nos referiremos a continuación.

\subsection{Reacciones paradójicas en el tratamiento de la tuberculosis ganglionar}

Durante el tratamiento de todas las formas de TBC pueden presentarse agravaciones inesperadas de la enfermedad que no significan fracaso de la terapia y generalmente no necesitan cambios en el tratamiento, aunque pueden requerir el agregado de corticoesteroides y que, en el caso de la asociación TBC-SIDA, pueden revestir especial gravedad. Habitualmente sólo se manifiestan por aumento de síntomas como fiebre y nuevos compromisos del estado general, aumento de las lesiones parenquimatosas, aparición de derrames pleurales inesperados, etc. Cuando afectan a la localización en el sistema nervioso central, como en la meningitis tuberculosa, pueden revestir especial gravedad. Su frecuencia es muy variable. Ha sido descrita en sólo un 2 a 3\% de los casos 
en la TBC pulmonar, a diferencia de las localizaciones extrapulmonares en las que se presenta en un $25 \%{ }^{27}$. En los pacientes usuarios de tratamientos con agentes anti-TNF alfa (factor de necrosis tumoral alfa) se han reportado $67 \%$ de RP y en los enfermos VIH $(+)$ hasta un $30 \%$.

En el caso de las adenopatías tuberculosas, la RP se define como el aumento de tamaño de los ganglios pre-existentes y/o desarrollo de fístulas de drenaje o aparición de otros linfonodos con posterioridad al inicio del tratamiento antituberculoso. Para catalogarla como RP se requiere de su aparición por lo menos después de 2 semanas de tratamiento antituberculoso efectivo ${ }^{25,27}$. En la TBC ganglionar ha sido descrita en un 15 a $25 \%$ de los pacientes VIH negativos.

En un estudio reciente de 467 pacientes con TBC ganglionar, Yu y cols. reportaron un $18 \%$ de RP, las que se presentaron principalmente en los primeros 2 meses de tratamiento (67\%), con una dispersión de 0 a 10 meses (27). Según se presenten antes o después de los 4 meses, estos autores las denominan RP precoces o tardías. Esta diferencia se establece porque es común que la aparición de una RP tardía se atribuya a fracaso del tratamiento, lo que induce muchas veces a prolongar la quimioterapia antituberculosa innecesariamente.

El mismo grupo surcoreano había publicado anteriormente una serie de 154 pacientes con TBC ganglionar de los cuales $24(15,6 \%)$ presentaron RP tardía al término del tratamiento ${ }^{25}$. De ellos $17 \%$ tenía baciloscopia positiva en la muestra obtenida por punción y 47,8\% PCR positiva en la biopsia al final del tratamiento (debida probablemente a ADN de bacilos no viables), pero la gran mayoría de ellos tenían los cultivos negativos, por lo tanto no se trataba de fracasos o reactivaciones bacteriológicas. El 91,7\% de los casos se resolvió en forma espontánea sin requerir más terapia. En menos del 10\% el cultivo fue positivo y requirieron de un retratamiento.

Se cree que las RP se deben a la alta carga antigénica liberada posteriormente al inicio del tratamiento antituberculoso, a lo que se sumaría la inefectividad en el clearance de las tubérculo proteínas o antígenos de los macrófagos portadores de bacilos de Koch, asociados a una demora en el reconocimiento antigénico por macrófagos "desfuncionalizados"25,26. En todo caso, se trataría de una manifestación de hipersensibilidad celular de tipo retardado mantenida frente a antígenos del Mycobacterium tuberculosis muertos.

La recomendación actual ante una RP tardía en la linfoadenitis tuberculosa es observar estrechamente su evolución por un período de 1 a 4 semanas. Si no muestran tendencia a resolverse se recomienda tomar nuevas muestras, por punción o biopsia y sólo si el cultivo es positivo se reiniciará el tratamiento antituberculoso de acuerdo a las pruebas de susceptibilidad ${ }^{27}$. En la gran mayoría de los casos no se recomienda prolongar la terapia más allá de sus plazos habituales de 6 meses.

En pacientes con molestias locales significativas, asociadas a inflamación de los tejidos vecinos se aconseja el empleo de corticoesteroides. También cuando se intenta evitar la fistulización de un ganglio muy inflamado o ante síntomas determinados por la compresión de estructuras vecinas, como estenosis tráqueo-bronquiales o disfagia por compresión esofágica en las adenopatías del mediastino. Generalmente se utilizan dosis bajas de prednisona $(\leq 0,5 \mathrm{mg} / \mathrm{kg})$ por plazos habitualmente no superiores a un mes ${ }^{6}$.

Finalmente, y como medida de rescate, hay reportes de casos exitosos con el uso de infliximab, que ha sido utilizado en escenarios graves (tuberculosis meníngea) cuando no ha existido respuesta al uso de corticoides en altas dosis ${ }^{28}$.

\section{Bibliografía}

1.- FARGA V, CAMINERO A. Tuberculosis. Editorial Mediterráneo, 3ra edición. Santiago y Buenos Aires. 2011.

2.- ILGAZLI A, BOYACI H, BASYIGIT I, YILDIZET F. Extrapulmonary tuberculosis: clinical and epidemiologic spectrum of 636 cases. Arch Med Res 2004, 35: 435-41.

3.- FONTANILLA J M, BARNES A, VON REYN C F. Current diagnosis and management of peripheral tuberculous lymphadenitis. Clin Infect Dis 2011; 53: 555-62.

4.- CDC. Reported Tuberculosis in the United States, 2014. Atlanta, GA: U.S. Department of Health and Human Services, CDC, Octubre 2015.

5.- PROGRAMA NACIONAL DE CONTROL Y ELIMINACIÓN DE LA TUBERCULOSIS. Informe de situación Chile 2013. [Internet]. Disponible en: http:// web.minsal.cl/sites/default/files/files/TUBERCULOSISINFORME\%202013.pdf

6.- JI YEON LEE. Diagnosis and Treatment of Extrapulmonary Tuberculosis. Tuberc Respir Dis 2015; 78: 47-55.

7.- CLEVENBERGH P. MAITREPIERRE I, SIMONEAU G, RASKINE L, MAGNIER JD, SANSON-LE-PORS $\mathrm{M} J$, et al. Lymph node tuberculosis in patients from regions with varying burdens of tuberculosis and human immunodeficiency virus (HIV) infection. Presse Med 2010; 39: e223-30.

8.- SMAOUI S, MEZGHANNIA M, HAMMAMIC M, ZALILAD N, MAROUANEA C, KAMMOUNA S, et al. Tuberculosis lymphadenitis in a southeastern region 
in Tunisia: Epidemiology, clinical features, diagnosis and treatment. Inter J Mycobacteriol 2015 4: 196-201.

9.- GONZÁLEZ O Y, TEETER L D, THANH B T, MUSSER J M, GRAVISS E A. Extrathoracic tuberculosis lymphadenitis in adult HIV seronegative patients: a population-based analysis in Houston, USA. Int J Tuberc Lung Dis 2003; 7: 987-93.

10.- BEM C. Human immunodeficiency virus-positive tuberculous lymphadenitis in Central Africa: clinical presentation of 157 cases. Int J Tuberc Lung Dis 1997; 1: $215-9$

11.- AGARWAL A K, SETHI A, SETHI D, MALHOTRA V, SINGAL S. Tubercular cervical adenitis: clinicopathologic analysis of 180 cases. J Otolaryngol Head Neck Surg 2009; 38: 521-7.

12.- POLESKY A, GROVE W, BHATIA G. Peripheral tuberculous lymphadenitis: epidemiology, diagnosis, treatment, and outcome. Medicine (Baltimore) 2005; 84: 350-62.

13.- MURRAY J F, NADEL J. Textbook of Respiratory Medicine, 6th Edition. Philadelphia, PA: Elsevier Saunders, [2016].

14.- KAZWALA R R, DABORN C J, SHARP J M, KAMBARAGE D M, JIWA S F, MBEMBATI N A. Isolation of Mycobacterium bovis from human cases of cervical adenitis in Tanzania: a cause for concern? Int J Tuberc Lung Dis 2001; 5: 87-91.

15.- SALVADOR F, LOS-ARCOS I, SÁNCHEZ-MONTALVÁ A, TÓRTOLA T, CURRAN A, VILLAR A, et al Epidemiology and Diagnosis of Tuberculous Lymphadenitis in a Tuberculosis Low-Burden Country. Medicine 2015, 94 (4): e509.

16.- DENKINGER C M, SCHUMACHER S G, BOEHME C C, DENDUKURI N, PAI M, STEINGART K R. Xpert MTB/RIF assay for the diagnosis of extrapulmonary tuberculosis: a systematic review and meta-analysis. Eur Respir J 2014; 44: 435-46.

17.- WORLD HEALTH ORGANIZATION. Xpert MTB/RIF assay for the diagnosis of pulmonary and extrapulmonary TB in adults and children: policy update. Geneva: World Health Organization; 2013.

18.- VALLEJO P, RODRÍGUEZ J C, SEARLE A, FARGA V. Ensayo Xpert MTB/RIF en el diagnóstico de tuberculosis. Rev Chil Enferm Respir 2015; 31: 127-31.

19.- SHIN J A, CHANG Y S, KIM H J, AHN C M, BYUN M K. Diagnostic utility of interferon-gamma release assay in extrapulmonary tuberculosis. Diagn Microbiol Infect Dis 2015; 82: 44-8.

20.- HASSAN T, MCLAUGHLIN A, O'CONNELL F, GIBBONS N, NICHOLSON S, KEANE J. EBUS-TBNA performs well in the diagnosis of isolated thoracic tuberculous lymphadenopathy. Am J Respir Crit Care Med 2011; 183: 136-7.

21.- MINISTERIO DE SALUD. Normas Técnicas Programa Nacional de Control de la Tuberculosis 2014, Chile.

22.- ASIMACOPOULOS E P, BERRY M, GARFIELD
B, ROESNER M, JEPSON A, MCCARTHY J, et al. The diagnostic efficacy of fine needle aspiration using cytology and culture in tuberculous lymphadenitis. Int J Tuberc Lung Dis 2010; 14: 93-8.

23.- CAMPBELL I A, ORMEROD L P, FRIEND J A, JENKINS P A, PRESCOTT R J. Six months versus nine months chemotherapy for tuberculosis of lymph nodes: final results. Respir Med 1993; 87: 621-3.

24.- Treatment of Tuberculosis, American Thoracic Society, CDC and Infectious Diseases Society of America June 20, 2003 /Vol. 52 /No. RR-11.

25.- PARK K H, LEE M S, LEE S O, CHOI S H, KIM Y S, WOO J H, et al. Incidence and outcomes of paradoxical lymph node enlargement after antituberculosis therapy in non-HIV patients. J Infection 2013; 67: 408-15.

26.- BELL L C, BREEN R, MILLER R F, NOURSADEGHI M, LIPMAN M. Paradoxical reactions and immune reconstitution inflammatory syndrome in tuberculosis. Intern J. Infect Dis 2015; 32: 39-45.

27.- YU S N, CHO O H, PARK K H, JUNG J, KIM Y K, LEE J Y, et al. Late paradoxical lymph node enlargement during and after anti-tuberculosis treatment in non-HIV infected patients. Int J Tuberc Lung Dis 2015; 19: 1388-94.

28.- BLACKMORE T K, MANNING L, TAYLOR W J, WALLIS R S. Therapeutic use of Infliximab in tuberculosis to control severe paradoxical reaction of the brain and lymph node. Clin Infect Dis 2008, 47: e83-5.

29.- KHANNA R, SHARMA A D, KHANNA S, KUMAR M, SHUKLA R C. Usefulness of ultrasonography for the evaluation of cervical lymphadenopathy. World J Surg Oncol 2011; 9: 29.

30.- CHOU C-H, YANG T-L, WANG C-P. Ultrasonographic features of tuberculous cervical lymphadenitis. J Medical Ultrasound 2014, 22, 158-63.

31.- FAIN O, LORTHOLARY O, DJOUAB M, AMOURA I, BABINET P, BEAUDREUIL J, et al. Lymph node tuberculosis in the suburbs of Paris: 59 cases in adults not infected by the human immunodeficiency virus. Int J Tuberc Lung Dis 1999; 3: 162-5.

32.- SINGH K K, MURALIDHAR M, KUMAR A, CHATTOPADHYAYA T K, KAPILA K, SINGH M $\mathrm{K}$, et al. Comparison of in house polymerase chain reaction with conventional techniques for the detection of Mycobacterium tuberculosis DNA in granulomatous lymphadenopathy. J Clin Pathol 2000; 53: 355-61.

Correspondencia a:

Dr. Felipe Aliaga Tapia

Servicio Enfermedades Respiratorias,

Instituto Nacional del Tórax.

José M. Infante 717, Providencia,

Santiago, Chile.

Email: felipealiaga@gmail.com 